\title{
Flexible work arrangements, work engagement, turnover intentions and psychological health
}

\author{
Carolyn Timms James Cook University, Australia \\ Paula Brough Griffith University, Australia \\ Michael O'Driscoll University of Waikato, New Zealand \\ Thomas Kalliath Australian National University, Australia \\ Oi Ling Siu Lingnan University, Hong Kong \\ Cindy Sit University of Hong Kong, Hong Kong \\ Danny Lo Shue Yan University, Hong Kong
}

\begin{abstract}
Flexible work arrangements (FWAs) are often written into company policies to demonstrate organisational sensitivity to potentially difficult interfaces between employees' work and non-work domains. The current research investigated employees' use of FWAs and relationship to work engagement, with turnover intentions and psychological strain also used as criterion variables for comparison purposes. A heterogeneous sample of Australian employees $(\mathrm{N}=823)$ responded to two waves of data collection separated by a 12-month interval. It was expected that supportive aspects of organisational culture would be consistent with increased employee utilisation of FWAs, high work engagement, low turnover and low levels of psychological strain, and the opposite would be found for hindering aspects of organisational culture. It was also expected that supportive organisational culture would demonstrate an enduring effect over time. In general, research findings supported these hypotheses. However, the research also identified a negative relationship between use of FWAs and work engagement over time. This suggests that take-up of FWAs is highly dependent on workplace cultural norms. The implications of these results are discussed.
\end{abstract}

Keywords: flexible work arrangements, organisational culture, work engagement

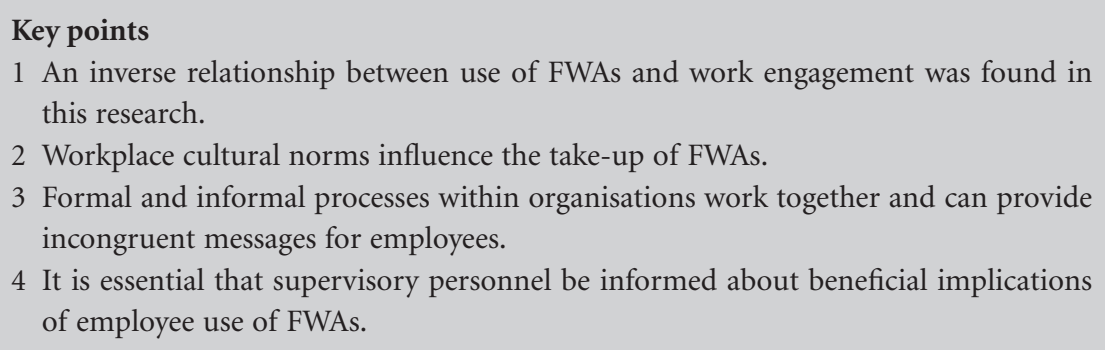

Correspondence: Dr Carolyn Timms, Psychology, School of Arts and Social Sciences, James Cook University, McGregor Road, Smithfield, 4870, Queensland, Australia; e-mail: carolyn.timms @jcu.edu.au

Accepted for publication 14 June 2013. 


\section{Introduction}

Work-life balance refers to manageability of the different domains of one's life so that they complement rather than compete with each other. Juggling responsibilities to work, family and community, as well as requirements for physical health and psychological wellbeing such as hobbies, exercise and other personal interests can create competing priorities in people's lives (e.g. Brough, O'Driscoll and Kalliath 2005). Unsatisfactory resolution of the tension generated by these competing priorities is referred to as work-life conflict (Carlson, Kacmar and Williams 2000). Work-life conflict is associated with exhaustion and psychological strain (Brough, O'Driscoll and Kalliath 2005) and leads to deleterious health outcomes, absenteeism and turnover (Bolger et al. 1989).

Kanter (1977) highlighted the interwoven nature of the different aspects of employees' lives and observed that it was inevitable that emotional states would permeate domain boundaries for better or for worse. Positive emotional states that permeate work and nonwork domains can augment and expand individuals' feelings of well-being and selfefficacy (O'Driscoll and Brough 2010; Thornthwaite 2004) thereby creating an upward spiral of positive affect. According to Carlson et al. (2006) this leads to a sense of mastery, which in turn empowers individuals and benefits organisations (see also, Harter, Schmidt and Hayes 2002).

Abbott, De Cieri and Iverson (1998) found that the organisational costs of ignoring the personal commitments and responsibilities of employees included high absenteeism and turnover (see also Brough 2005). It follows that policies designed to enhance employees' autonomy and integration of their work and non-work lives will be beneficial to organisations (De Cieri et al. 2005). Carless and Wintle (2007) suggested that the provision of flexible solutions such as flexible hours, career paths and telecommuting can make organisations more attractive to prospective employees (see also, Casper and Buffardi 2004; Cook 2009). Thus it is in the best interests of organisations to provide the means by which employees can manage disparate responsibilities, in order to attract and retain skilled personnel.

\section{Flexible work arrangements}

Flexible work arrangements (FWAs) are strategies by which employees can better balance demands from multiple domains (Allen 2001; Brough, O’Driscoll and Kalliath 2005). Examples of FWAs include: flexitime (e.g. employees choose their start and finishing times of work), compressed work week (e.g. employees choose to work four long days instead of five regular days), telecommuting (e.g. employees work from home via information communication technology (ICT)) and finally, part-time work. Examples of other flexible employment options that organisations can provide are more family-specific and include parental leave and on-site childcare facilities. The current study focuses on FWAs, as previous research has found that these provisions are also attractive to employees who do not have family responsibilities but who nevertheless desire flexibility between their work and non-work lives (Brough and O'Driscoll 2010; Carless and Wintle 2007; Hall 1990). 


\section{Organisational culture}

Articulation of FWA policies in company documents is beneficial for organisations in terms of reputation (as employee friendly workplaces) and attracting potential employees (Carless and Wintle 2007). However, Dikkers et al. (2004) found that actual access or use of FWAs was influenced by the pre-existing culture of a workplace which (because it is usually psychological in nature and informal in implementation) may have little resemblance to official policy (Behson 2005; Kirby and Krone 2002). Consequently once they are employed, workers acquire an insider's understanding of the difference between written policies and unwritten practices embedded in organisational norms (Denison 1996). Haggerty and Wright (2010) suggested that informal processes within the firm constitute powerful signals that adjust employee behaviour.

According to Denison (1996) this process includes psychological and sociological processes. This has parallels with the literature on psychological climate, which refers to the impact of organisational systems on individuals in the workplace. Parker et al. (2003) also observed that organisational culture could more accurately be described as 'psychological climate' because it is related to many individual outcomes including psychological wellbeing and employee performance. Parker and colleagues found that psychological climate is built on relationships (leader, work-group and organisation), work role and job requirements. They found that an optimal organisational culture was generated when people worked well together to overcome difficulties and challenges. Bowen and Ostroff (2004) suggested that human resource management (HRM) departments can play an important role in conveying messages that are consistent in both formal and informal organisational systems. This is an important aspect of organisational productivity as complications facing people in the work environment may emanate from outside work and the availability of FWAs could feature as workable solutions to these problems.

Parker et al.'s (2003) optimal organisational culture would be defined by Dikkers et al. (2004) as a supportive culture. A supportive culture is one which commonly values nonwork aspects of people's lives and seeks to accommodate the multiple needs of workers so that they will be psychologically present for work tasks (i.e. recognition of work-life balance). On the other hand, Dikkers et al. defined a hindering organisational culture as requiring workers to prioritise work over their non-work needs. This can take the form of expectations that workers will put extra time into ensuring that work will be done (time expectations) or norms where workers get a clear message that prioritising personal needs will have negative consequences for their career progression (Dikkers et al.). It is therefore observed that because supportive and hindering cultures affect people's responses to their work and general functioning outside of work, both contribute to psychological climate within an organisation (see Denison 1996; Parker et al. 2003). Hence, while the present paper refers to organisational culture, overlaps with organisational and psychological climate are also acknowledged.

Behson (2005) observed that an organisational focus on providing a supportive environment would be rewarded by increases in workers' satisfaction, decreased stress and turnover intentions. Behson thus emphasised employee empowerment via the provision of 
organisational policies which enabled workers to be autonomous in respect to achieving work goals and performance (see also, Laschinger and Finegan 2005). Investigations conducted by Casper et al. (2004) and Laschinger and Finegan (2005) demonstrated that immediate managers (supervisors) assume an important function in the translation of cultural attitudes toward using FWAs within organisations (see also Thompson, Brough and Schmidt 2006). Hindering organisational cultures convey strong signals to employees that accessing FWAs may have repercussions in terms of their personal career, may create extra burdens (work) for their colleagues, and produce work-group resentment (e.g. McDonald, Pini and Bradley 2007; Thompson et al. 2004).

An example of such a culture was provided by Timms et al. $(2008,156)$ who described a 'coke and pizza culture' in the ICT industry (where it was customary for fast food to be brought in to expedite completion of projects after hours). According to Timms et al. this well-established norm was perceived as a major barrier to career advancement by professional women who, because of their non-work responsibilities, were unavailable for frequent late night work. The women observed that their career advancement was stymied by supervisors' negative judgments of their organisational commitment (see also Thornthwaite 2004).

Kirby and Krone (2002) observed that in some organisations employees are pressured not to use policies designed to facilitate their work-life balance and (in reference to telecommuting) suggested that recognition may only be afforded to 'visible' work, rather than that work conducted offsite. McDonald, Pini and Bradley (2007) suggested that actual reasons for use of FWAs might moderate supervisory judgments of employee commitment. For example in McDonald's qualitative study, some respondents who used FWAs for the purpose of accommodating tertiary study (rather than caring for children) confidently commented that their personal career options would not be affected because their reasons did not include family responsibilities. Implicit within such a viewpoint is the widely accepted opinion that family commitments dilute employees' commitment to the organisation (e.g. Allen 2001; Beauregard and Henry 2009).

\section{Work engagement}

According to Salanova and Schaufeli (2008) the presence of work engagement among workers is an indicator of their intrinsic motivation. This is consistent with the theory of self-determination (Ryan and Deci 2000), which emphases the social context in which employees are proactive, empowered and engaged and the psychological climate aspect of organisational culture previously described by Parker et al. (2003). Employees who are engaged in their work find it energising, they experience a sense of pride in what they do, time at work passes quickly and they have a sense of personal fulfilment (Biggs, Brough and Barbour 2013; Ryan and Deci 2001; Saks 2006). However, people's lives inevitably extend beyond their work. Sonnentag et al. (2008) observed that a key factor in employee engagement was the ability to 'switch off' or psychologically detach from work during non-work time. Typically psychological detachment involves people's social relationships and activities such as catching up with friends or pursuing hobbies or other interests. 
In addition, most employees have other responsibilities that must be attended to and for which they must be psychologically present, such as dependent children and/or other family matters, household tasks, and sport. Sonnentag et al. (2008) found that employees who were unable to achieve detachment from their work experienced a corresponding lowering of their work engagement. It is therefore observed that a long-hours work culture described by a number of researchers (McDonald, Pini and Bradley 2007; O'Driscoll, Brough and Kalliath 2004; Peetz and Allan 2005) could potentially erode employees' engagement with work.

Researchers have previously found that job satisfaction is a good predictor of employees' intentions to stay and it is also associated with low rates of absenteeism (e.g. Allen 2001; Brough, O’Driscoll and Kalliath 2005). Therefore it remains a parsimonious outcome measure of the most basic level of overall workplace health. However, job satisfaction in and of itself does not sufficiently capture the positive energy that is found in workplaces where workers are thriving (Schaufeli and Bakker 2003). Schaufeli and Bakker's description of an upward positive spiral where work engagement and self-efficacy lead to improved performance in both work and family domains is one of synergy and demonstrates some similarity with May, Gilson and Harter's $(2004,11)$ 'engagement of the human spirit at work'. Similarly, Carlson et al. (2006) suggested that the feeling of mastery gained through personal accomplishment contributed benefits across domains, thus empowering people to rise to challenges. According to Laschinger and Finegan (2005) empowerment of workers provides the means by which organisations can address shortages of skilled workers, by attracting highly qualified applicants and reducing absenteeism and turnover. This echoes a common theme within organisational research that engaged workers are less likely to seek alternative employment (Maslach, Schaufeli and Leiter 2001; Schaufeli 2004; Timms and Brough 2013).

According to the job demands resources theory (JD-R, Bakker and Demerouti 2007), resources within the work environment provide a counterbalance to work demands and employee mental health. The theoretical linkage between FWAs and work engagement therefore lies in the discretion afforded to employees as to how work is done (Behson, 2005) and how workers can achieve some mechanisms of control and autonomy.

\section{The current research}

Empirical investigations of the use of FWAs have primarily included job satisfaction as an outcome variable. Job satisfaction has demonstrated significant utility within studies of the importance of supportive work environments, effective work-life balance policies and work performance (e.g. Allen 2001; Brough, O’Driscoll and Kalliath 2005). However, these investigations are unable to assess optimal workplace psychological health. Some research has included psychological strain (e.g. Brough 2005; Brough et al. 2013; Lapierre and Allen 2006) or burnout (e.g. Sonnentag, Kuttler and Fritz 2010) as health outcome measures. Schaufeli (2004) previously observed that, just as the absence of disease does not indicate physical health, the absence of strain is not indicative of psychological well-being. 
Therefore the current study anticipates that the inclusion of a specific psychological health criterion variable (work engagement) will provide more accurate information concerning the impact of FWAs on psychological well-being.

Drawing on these previous findings and extrapolating them to include the complex relationships of work engagement, use of FWAs and organisational culture (supportive and hindering); the following hypotheses are advanced for this research:

Hypothesis 1: Respondents who report that their workplace culture is distinguished by expectations that employees will put in long hours at work and their career will be negatively impacted if they use FWAs, will be unlikely to use them. They will demonstrate (a) lower work engagement, (b) higher turnover intentions and (c) higher psychological strain.

Hypothesis 2: Respondents who report that their workplace culture is supportive will be more likely to use FWAs. They will demonstrate (a) higher work engagement,

(b) lower turnover intentions and (c) lower psychological strain.

Finally, there is a contextual component of the current research which introduces an exploratory aspect. Coincidentally the two data collection phases reported here were conducted in Australia in March 2008 (time 1) and then in March 2009 (time 2). Australia began to be affected by the Global Financial Crisis (GFC) in September 2008. While Australia's economic situation fared better than some other comparable countries, the Australian government did report declines in both employment figures and consumer confidence (Australian Senate House Committee, 2009). Rafferty, Schutz and Yu (2010) noted that in such times government and business priorities tend to focus on physical needs rather than human capital and employees tend to be regarded as expendable, leading to staff cutbacks. The current research was directly impacted by the GFC due to restructuring and employee reductions by two participating organisations. Therefore, an additional aim of the current study is to investigate any changes in responses between the two phases of the survey that may be attributed to the 2008-09 Global Financial Crisis.

\section{Method}

\section{Sample and procedure}

The sample consisted of employees from eight Australian organisations representing banking, education, public service and community service, who responded to two identical self-report surveys with a 12-month interval between administrations. The primary research sites were located in Queensland and the Australian Capital Territory; however, the organisations surveyed included employees in all eastern states of Australia. Response rates varied, ranging from $10 \%$ to $52 \%$ across the participating organisations, with an average response rate of $33 \%$. It was found that those organisations that posted individual questionnaires directly to employees achieved higher response rates than those that distributed surveys sent in a mass mailout. In the lag between data collections, the GFC began to have an impact in Australia, leading to the withdrawal of two participating 
organisations from this research, therefore missing the time 2 data collection. A total $N=$ $823(21.5 \%)$ workers were matched from the time 1 (T1) and time 2 (T2) survey responses.

Of the 823 matched respondents, the majority $(72 \%)$ were female $(n=593)$. Respondents ranged in age from 20 to 70 years, with an average age of 43 years $(S D=10.30)$. At time 1, $351(43 \%)$ respondents indicated that they were single (with no commitments to spouse and/or dependants) and $57 \%(n=472)$ indicated they had family commitments. Forty-three percent $(n=352)$ of respondents had a university or college degree and $70 \%$ of these $(n=248)$ had at least one postgraduate qualification. The majority of respondents indicated they were working in a full-time position $(n=613 ; 75 \%)$. The mean tenure reported by respondents was 11 years $(S D=9.53)$.

\section{Measures}

\section{Organisational culture}

Eleven items from Dikkers, Geurts, Den Dul, and Kompier's (Dikkers et al., 2004) organisational culture measure were included. The measures consist of three subscales: organisational support (four items) - for example, 'In general, this company is considerate towards employees' private situation'; negative career consequences (hindrance; three items) - 'In this company, employees who [temporarily] reduce their working hours for private reasons are considered less ambitious'; and time expectations (hindrance; four items) - 'In order to be taken seriously in this company, employees should work long days and be available all the time'. Respondents reported how much they agreed with the statements on a 5 -point Likert-type scale from $1=$ 'totally disagree' to $5=$ 'totally agree'. High scores are therefore indicative of a supportive or hindering organisational culture. Each subscale demonstrated adequate internal reliability (Cronbach's alphas): organisational support $=0.87$ (time 1$)$ and 0.88 (time 2$)$; negative career consequences $=0.88($ time 1$)$ and 0.90 (time 2), and time expectations $=0.86$ (time 1$)$ and 0.88 (time 2).

\section{Supervisor support}

The four-item supervisor support scale developed by O'Driscoll, Brough, and Kalliath (O'Driscoll 2000) was included. The items ask how often respondents had received support in relation to work-related problems in the previous three months. Items referred to helpful information or advice (informational support), sympathetic understanding and concern (emotional support), clear and helpful feedback (feedback support) and practical assistance (practical support). Respondents answered on a 6-point frequency scale, where $1=$ 'never' and $6=$ 'all the time'. High scores on the aggregate scale indicated high supervisor support. Internal consistencies (Cronbach's alphas) for supervisor support were 0.94 (T1) and 0.95 (T2).

\section{Turnover intention}

Brough and Frame's (Brough and Frame, 2004) three-item turnover intentions measure was included. An example item is: 'How often have you seriously considered leaving your 
current job in the past six months?' Respondents answered on a 5-point Likert-type scale ranging from 1 = 'not at all' to 5 = 'a great deal'. High scores therefore indicate high turnover intentions. Internal consistencies (Cronbach's alphas) for the current study were 0.82 (T1) and $0.84(\mathrm{~T} 2)$.

\section{Flexible work arrangements}

The four-item FWA subscale from Allen's (2001) 10-item measure of work-life organisational policies was included. The four items referred to flexitime, compressed working week, telecommuting, and part-time work. Respondents selected one of four responses for each item: 1) not offered but I don't need it; 2) not offered but I could use it; 3 ) offered but not used; and 4) offered and I use it. To derive a score for benefit availability, responses ( 1 ) and (2) were coded ' 0 ' and responses (3) and (4) were coded ' 1 '. Total benefit availability was computed by summing availability scores for all four items. The score for usage was derived by scoring responses (1), (2), and (3) as ' 0 ' and response (4) as ' 1 '. Total benefit usage was computed by summing usage scores across all four items. The categorical nature of FWA availability and usage scores makes the computation of reliability estimates irrelevant.

\section{Work engagement}

Engagement was measured with the 9-item short version of the Utrecht work engagement scale (UWES; Schaufeli and Bakker 2003). An example item is 'I find the work that I do full of meaning and purpose'. Respondents answered on a 7-point Likert-type scale, from $0=$ 'never' and $6=$ 'always'. High scores therefore indicate higher levels of work engagement. Internal consistency for the UWES was 0.91 (time 1 and time 2).

\section{Anxiety/depression}

The four item anxiety/depression subscale (Kalliath, O'Driscoll and Brough 2004) from the General Health Questionnaire (GHQ, Goldberg 1972) was utilised as a measure of psychological strain. The GHQ is a widely used measure of psychological strain that has consistently reported high levels of internal reliability in previous studies (e.g. Kalliath, O'Driscoll and Brough 2004). Items from the GHQ were prefaced with the stem 'Have you recently experienced the following in the past few weeks . . . and a sample item from the anxiety/depression subscale is 'been feeling unhappy or depressed?' The anxiety/ depression items were measured on a 4 -point frequency scale with $0=$ 'more so than usual' and $3=$ 'much less than usual'. In the current study anxiety/depression achieved a Cronbach's alpha of 0.81 (time 1) and 0.80 (time 2).

\section{Results}

Table 1 provides information in regard to the reported availability and use of FWAs at time 1 and time 2. It is observed that while respondents' awareness of the availability increased at time 2, reported usage decreased over time. In regard to reported overall 
Table 1 Availability and use of FWAs in the two phases of the survey $(\mathrm{N}=823)$

\begin{tabular}{|c|c|c|c|c|c|c|c|c|}
\hline & \multicolumn{4}{|c|}{ Time 1} & \multicolumn{4}{|c|}{ Time 2} \\
\hline & \multicolumn{2}{|c|}{ Availability } & \multicolumn{2}{|l|}{ Use } & \multicolumn{2}{|c|}{ Availability } & \multicolumn{2}{|l|}{ Use } \\
\hline & $\mathrm{n}$ & $\%$ & $\mathrm{n}$ & $\%$ & $\mathrm{n}$ & $\%$ & $\mathrm{n}$ & $\%$ \\
\hline Flexitime & 403 & 49.0 & 344 & 41.8 & 628 & 76.3 & 126 & 15.3 \\
\hline Part-time work & 540 & 65.6 & 248 & 30.1 & 623 & 75.7 & 203 & 24.7 \\
\hline Compressed work week & 137 & 16.6 & 115 & 14.0 & 464 & 56.4 & 70 & 8.5 \\
\hline Telecommuting & 213 & 26.0 & 127 & 15.0 & 405 & 49.2 & 65 & 8.0 \\
\hline At least one FWA & 709 & 86.1 & 465 & 57.0 & 787 & 95.6 & 331 & 40.0 \\
\hline
\end{tabular}

Table 2 Means, standard deviations, comparison and effect size of study variables

\begin{tabular}{|c|c|c|c|c|c|c|}
\hline & \multicolumn{2}{|c|}{ Time 1} & \multicolumn{2}{|c|}{ Time 2} & \multirow[t]{2}{*}{ Paired samples $t$ test } & \multirow{2}{*}{$\begin{array}{l}\text { Eta-squared } \\
\eta^{2}\end{array}$} \\
\hline & $\mathrm{M}$ & SD & M & SD & & \\
\hline Supervisor support & 3.70 & 1.32 & 3.64 & 1.35 & $n s$ & \\
\hline Organisational support & 4.69 & 1.10 & 4.61 & 1.16 & $n s$ & \\
\hline Organisational time demands & 3.15 & 1.05 & 3.18 & 1.09 & $n s$ & \\
\hline Negative career consequences & 3.04 & .94 & 3.06 & .98 & $n s$ & \\
\hline Turnover intentions & 2.04 & 1.02 & 2.08 & 1.06 & $n s$ & \\
\hline Work engagement & 3.25 & .88 & 3.86 & .88 & $21.36^{* * *}$ & .12 \\
\hline Anxiety/depression & .75 & .66 & .82 & .69 & $n s$ & \\
\hline Use of FWAs & 1.00 & 1.10 & .60 & .85 & $-11.68^{\star * *}$ & .14 \\
\hline Availability of FWAs & 1.57 & 1.10 & 2.58 & 1.21 & $20.64^{\star * *}$ & .12 \\
\hline
\end{tabular}

Probability for paired samples $t$ test was set at 0.006 (Bonferroni adjustment) with a critical value of $t=3.09$ two tailed; ${ }^{* * *} p<0.001$.

availability and use of FWAs reported in Table 1, these figures represent the creation of dummy variables where in regard to availability $(0=$ no FWAs available and $1=$ at least one FWA is available), and in regard to use $(0=$ do not use FWAs and $1=$ use at least one FWA).

Table 2 provides descriptive information and mean score difference testing for the research variables at both time 1 and time 2 . Mean scores were statistically tested by paired samples $t$ tests with a Bonferroni adjustment probability level of 0.006 or $t=3.09$ critical value. At time 2 respondents reported significantly higher levels of work engagement than at time 1, more awareness of availability of FWAs and yet reduced use of FWAs. These tests produced large effect sizes; all other cross-time differences were not statistically significant.

The results of bivariate correlations of the research variables are provided in Table 3. It is noted that most relationship directions are consistent with the study hypotheses. 
Asia Pacific Journal of Human Resources 53

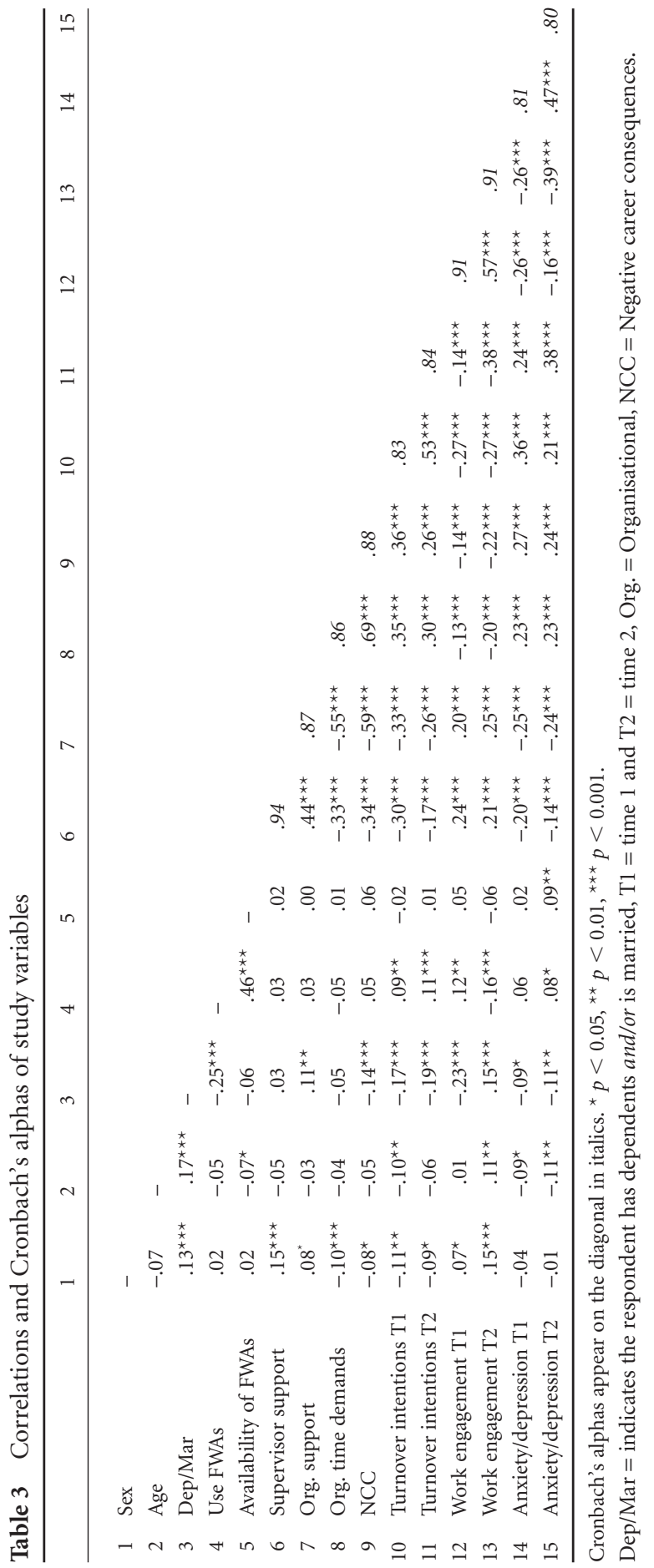


Negative relationships between hindering elements of organisational culture (time expectations and negative career consequences) and use of FWAs are consistent with our predictions (hypothesis 1); however, the relationships are small or non-significant. Surprisingly, a negative relationship was found between use of FWAs and work engagement (hypothesis 2 ). The use of FWAs at time 1 has a positive relationship with work engagement (time 1) and a negative relationship with work engagement at time 2 . Some explanations for this finding will be addressed in the discussion.

Initial data cleaning involving residual scatter-plots associated with the regression analyses revealed no issues in regard to heteroskedastisity or common method variance. Both cross-sectional (T1) and longitudinal hierarchical multiple regression analyses were conducted in order to compare our results with published (mostly cross-sectional) findings and to also test the research hypotheses over time - a point that is still repeatedly requested (e.g. Brough and O'Driscoll 2010). The longitudinal analyses tested the ability of the time 1 predictor variables to estimate the time 2 criterion variables. This provides a sense of their capacity to endure over time. Gender, age and single/family status acted as controls in all regression equations. Summaries of these results are presented in Tables 4 and 5. The cross-sectional analyses (time 1 variables, Table 4) indicated that turnover intentions were associated with being single, experiencing a 'long work hours' culture and a lack of supervisor support. Work engagement was associated with being single, experiencing a supportive supervisor and a supportive organisation. Anxiety/depression

Table 4 Summary of results for hierarchical regression analyses testing the relationship of study variables in the prediction of turnover intentions, work engagement and anxiety/depression time 1 cross-sectional $(\mathrm{N}=823)$

\begin{tabular}{|c|c|c|c|c|c|c|c|c|c|c|c|c|c|}
\hline & & \multicolumn{12}{|c|}{ Cross-sectional analyses (time 1 ) } \\
\hline & & \multicolumn{4}{|c|}{ Turnover intentions } & \multicolumn{4}{|c|}{ Work engagement } & \multicolumn{4}{|c|}{ Anxiety/depression } \\
\hline & & $\mathrm{B}$ & $\beta$ & $\mathrm{R}^{2}$ & $\Delta \mathrm{R}^{2}$ & $\mathrm{~B}$ & $\beta$ & $\mathrm{R}^{2}$ & $\Delta \mathrm{R}^{2}$ & $\mathrm{~B}$ & $\beta$ & $\mathrm{R}^{2}$ & $\Delta \mathrm{R}^{2}$ \\
\hline \multirow[t]{4}{*}{ Step 1} & & & & .03 & $.04^{* * *}$ & & & .05 & $.06^{* * *}$ & & & .01 & $.01^{\star}$ \\
\hline & Gender & -.19 & $-.08^{\star}$ & & & .16 & $.08^{*}$ & & & -.03 & -.02 & & \\
\hline & Age & -.01 & $-.07^{\star}$ & & & .00 & .05 & & & -.01 & $-.08^{\star}$ & & \\
\hline & Dep/Mar & -.27 & $-.13^{* * *}$ & & & -.41 & $-.24^{\star \star \star}$ & & & -.10 & $-.07^{\star}$ & & \\
\hline \multirow[t]{9}{*}{ Step 2} & & & & .19 & $.17^{\star * *}$ & & & .12 & $.07^{\star * *}$ & & & .11 & $.09^{\star * *}$ \\
\hline & Gender & -.08 & -.04 & & & .09 & .05 & & & .01 & .01 & & \\
\hline & Age & -.01 & $-.08^{\star}$ & & & .01 & .06 & & & -.01 & $-.08^{\star}$ & & \\
\hline & Dep/Mar & -.18 & $-.09^{* *}$ & & & -.42 & $-.24^{\star * *}$ & & & -.05 & -.04 & & \\
\hline & Sup support & -.13 & $-.17^{\star * *}$ & & & .11 & $.16^{* * *}$ & & & -.04 & $-.09^{*}$ & & \\
\hline & Org. support & -.08 & $-.09^{\star}$ & & & .11 & $.13^{\star \star}$ & & & -.07 & $-.12^{\star \star}$ & & \\
\hline & Org. time dem. & .15 & $.16^{\star *}$ & & & .01 & .01 & & & .03 & .05 & & \\
\hline & $\mathrm{NCC}$ & .12 & $.11^{\star}$ & & & -.04 & -.04 & & & .09 & $.13^{*}$ & & \\
\hline & Use of FWAs & .14 & $.07^{\star}$ & & & .06 & .06 & & & .07 & .05 & & \\
\hline
\end{tabular}

${ }^{\star} p<0.05,{ }^{* *} p<0.01,{ }^{* *} p<0.001$. Dep/Mar $=$ indicates the respondent has dependents and/or is married, $\mathrm{T} 1=$ time 1 , Org. $=$ Organisational, Sup $=$ Supervisor, $\mathrm{NCC}=$ Negative career consequences. 
Table 5 Summary of results for longitudinal hierarchical regression analyses testing the relationship of study variables time 1 in the prediction of turnover intentions, work engagement and anxiety/depression time 2 longitudinal $(\mathrm{N}=823)$

\begin{tabular}{|c|c|c|c|c|c|c|c|c|c|c|c|c|c|}
\hline & & \multicolumn{4}{|c|}{ Turnover intentions $\mathrm{T} 2$} & \multicolumn{4}{|c|}{ Work engagement $\mathrm{T} 2$} & \multicolumn{4}{|c|}{ Anxiety/depression T2 } \\
\hline & & B & $\beta$ & $\mathrm{R}^{2}$ & $\Delta \mathrm{R}^{2}$ & B & $\beta$ & $\mathrm{R}^{2}$ & $\Delta \mathrm{R}^{2}$ & B & $\beta$ & $\mathrm{R}^{2}$ & $\Delta \mathrm{R}^{2}$ \\
\hline \multirow[t]{2}{*}{ Step 1} & & & & .29 & $.29^{* * *}$ & & & .33 & $.33^{\star * *}$ & & & .23 & $.23^{* * *}$ \\
\hline & $\mathrm{T} 1$ criterion & .56 & $.54^{\star * *}$ & & & .58 & $.58^{\star * *}$ & & & .50 & $.48^{* * *}$ & & \\
\hline \multirow[t]{5}{*}{ Step 2} & & & & .30 & $.01^{* *}$ & & & .44 & $.11^{* * *}$ & & & .24 & $.01^{* *}$ \\
\hline & $\mathrm{T} 1$ criterion & .54 & $.51^{\star * *}$ & & & .65 & $.64^{* * *}$ & & & .66 & $.46^{\star * *}$ & & \\
\hline & Gender & -.07 & -.03 & & & .15 & $.07^{\star \star}$ & & & .03 & .02 & & \\
\hline & Age & .00 & .00 & & & .01 & $.07^{\star}$ & & & .00 & -.06 & & \\
\hline & Dep/Mar & -.23 & $-.11^{\star * *}$ & & & .54 & $.30^{\star * *}$ & & & -.11 & $-.08^{\star}$ & & \\
\hline \multirow[t]{10}{*}{ Step3 } & & & & .31 & $.02^{\star *}$ & & & .47 & $.03^{\star * *}$ & & & .26 & $.03^{* * *}$ \\
\hline & $\mathrm{T} 1$ criterion & .49 & $.47^{* * *}$ & & & .64 & $.63^{* * *}$ & & & .60 & $.42^{* * *}$ & & \\
\hline & Gender & -.05 & -.02 & & & .14 & $.07^{\star}$ & & & .04 & .03 & & \\
\hline & Age & .00 & .01 & & & .01 & $.06^{\star}$ & & & .00 & -.06 & & \\
\hline & Dep/Mar & -.19 & $-.09^{\star *}$ & & & .41 & $.23^{* * *}$ & & & -.06 & -.04 & & \\
\hline & Sup support & .02 & .02 & & & .01 & .02 & & & .00 & .00 & & \\
\hline & Org. support & -.04 & -.04 & & & .05 & .07 & & & -.05 & -.08 & & \\
\hline & Org. time dem. & .12 & $.12^{\star *}$ & & & -.04 & -.05 & & & .05 & .08 & & \\
\hline & NCC & -.03 & -.02 & & & .02 & .02 & & & .02 & .02 & & \\
\hline & Use of FWAs & .05 & .06 & & & -.13 & $-.17^{\star \star \star}$ & & & .05 & $.08^{*}$ & & \\
\hline
\end{tabular}

Time 1 equivalent variable is the time 1 equivalent of time 2 outcome variables (Turnover intentions, Work engagement and Anxiety/depression). ${ }^{*} p<0.05,{ }^{* *} p<0.01,{ }^{* * *} p<0.001$.

$\mathrm{Dep} / \mathrm{Mar}=$ indicates the respondent has dependents and/or is married, $\mathrm{T} 1=$ time 1 and $\mathrm{T} 2=$ time 2, Org. = Organisational, NCC $=$ Negative career consequences.

was associated with a lack of supervisor support and negative career consequences. The cross-sectional regression analyses achieved $F(8,784)=24.90, p<0.001$ for turnover intentions with the model explaining $19 \%$ of the variance, $F(8,786)=14.89, p<0.001$ for work engagement with the model explaining $12 \%$ of the variance; and $F(8,782)=11.53$, $p<0.001$ for anxiety/depression with the model explaining $10 \%$ of the variance.

Summaries of the longitudinal multiple regression analyses are presented in Table 5. In all cases the time 1 criterion variables (step 1) were the strongest predictors of their time 2 equivalents, with $R^{2}$ change observations revealing that minimal variance was contributed by the subsequent predictor variables. Similar to the cross-sectional analyses (Table 4), turnover intentions were associated with being single and experiencing a 'long work hours' culture. Work engagement at time 2 was predicted by being married and/or having children. Most interestingly, non-use of FWAs at time 1 was a significant predictor of work engagement at time 2. The longitudinal regression analyses achieved $F(9,779)=39.91$, $p<0.001$ for turnover intentions with the model explaining $31 \%$ of the variance, $F(9,785)=77.60, p<0.001$ for work engagement with the model explaining $47 \%$ of the variance, and $F(9,778)=30.94, p<0.001$ for anxiety/depression with the model explaining $26 \%$ of the variance. 


\section{Discussion}

This research assessed relationships between the type of organisational culture (support versus hindrance), employees' use of FWAs and their subsequent experiences of work engagement, turnover intentions and psychological strain. Findings in respect to hypotheses were mixed. Contrary to expectations, use of FWAs appeared to have minimal relationships with both turnover intentions and psychological strain. In addition, contrary to expectations (hypothesis 2) the use of FWAs contributed to reduced work engagement over time. Consistent with hypothesis 1, we found negative relationships between the use of FWAs and organisational hindrance. The predictions that employees' intentions to turnover would reflect a lack of supervisor and organisational support was supported in the cross-sectional analysis using T1 data, but was not supported over time (hypothesis 1). In regard to turnover intentions, organisational time expectations were predictive in both the cross-sectional analysis (T1 data) and over time, whereas negative career consequences only demonstrated significance in the cross-sectional analysis (hypothesis 1). Negative career consequences were similarly only predictive of anxiety/depression in the crosssectional analysis but not over time.

The present study highlights the importance of a supportive organisational culture in attenuating employees' intentions to turnover and the development of psychological strain. It also serves to demonstrate that organisational expectations that employees will work long hours have a direct and robust relationship with turnover intentions. The current findings support previous research suggesting that the presence of work engagement among workers is an important signal to management that the organisation is functioning well in terms of communication, support and meeting the expectations of employees (Saks 2006; Schaufeli 2004). Therefore it is observed that work engagement provides researchers with a measure of the success, or otherwise, of organisational attempts to combine policies and practice.

\section{FWAs and organisational culture}

Literature on the use of FWAs by employees suggests that these policies offer employees opportunities to balance their divergent needs in an autonomous manner (Behson 2005). However, the current study suggests that employees may not consider that FWAs are real options, due to informal processes within organisations that do not support their use (Kirby and Krone 2002; Thompson et al. 2004). In terms of the JD-R theoretical perspective (Bakker and Demerouti 2007), FWA provision could ostensibly be seen as an employee resource. On the other hand, it was apparent that without a supportive work environment, the presence of FWAs within organisational policy may well constitute an extra burden on employees. This is because formal and informal message pathways within organisations may compete with each other, leaving employees in the position where the choice to use FWAs (supposedly in place to assist them in balancing the domains of their life) affects their future career prospects and supervisory judgments on their commitment (see Kirby and Krone 2002). Peetz and Allan (2005) found that flexitime in particular had contributed to a firm's long hours culture. This had happened as the boundaries of 
previously standardised working hours had become blurred. Employees compared the perceived commitment of their colleagues (who started work earlier/finished later/skipped rest and meal breaks) to their own commitment and felt compelled to work longer hours. It is possible that some explanation for the current finding that work engagement was negatively associated with the use of FWAs is to be found in such informal message pathways.

This finding is inconsistent with previous literature advocating incorporation of FWAs in company policies. For example, Abbott, De Cieri and Iverson (1998) suggested that organisations should introduce family-friendly policies (including FWAs) in the interests of raising employee satisfaction and lowering turnover. Cook (2009) suggested that offering FWAs might well be viewed by employees as a message that their contribution to the organisation is respected and valued (see also Brough, O'Driscoll and Kalliath 2005). According to Laschinger and Finegan (2005), any message conveying respect for employees will be empowering and will build trust, thus contributing to work engagement. The current findings suggest that FWA provision within company policy has satisfied a requirement that the organisation be seen to be sensitive to the needs of employees. However, this provision is juxtaposed with the grinding reality that successful execution of work necessarily requires physical presence for long hours in the workplace. The presence of FWAs within organisational policy may well constitute an incongruent message that actually increases burdens on employees. Therefore, the strong message of the current research is that FWA provision without con-current supportive environments is unlikely to provide any of the positive outcomes suggested in previous research.

\section{Organisational culture, use of flexible solutions and work engagement}

Dikkers et al. (2004) found that high support (organisational and supervisor) occurred in tandem with high hindrance (time expectations and negative career consequences) and concluded that it was possible these two informal dimensions could co-exist within the experience of employees. Thus, organisations may recognise conflicting inter-domain demands on employees, and provide and encourage the use of flexible solutions to address employee problems. However, they also manage to convey a message of a company perception that those employees who do not work extra hours are not as seriously committed to their job and therefore could not be considered for promotion (e.g. Beauregard and Henry 2009; Kirby and Krone 2002). Inevitably this perception must be associated with cynical judgments in regard to organisational integrity and reliability on the part of employees. Our cross-sectional results support this conclusion in that hindrance and support were both significant predictors of turnover intentions. Furthermore, the finding that the actual use of FWAs was also a predictor of turnover intentions and non-use of FWAs was a predictor of work engagement, suggests that respondents did not necessarily find using FWAs a congenial solution to their work-life interface issues.

Behson (2005) noted that informal mechanisms within organisations are far more influential in terms of employee outcomes than are formal mechanisms. In addition, previous research has observed that immediate supervisors are the most visible (Cook 2009) 
and influential (McDonald, Pini and Bradley 2007; Thompson, Brough and Schmidt 2006) representatives of organisational policies. Casper et al. (2004) commented that supervisors are often poorly informed as to the beneficial nature of FWAs. It is, therefore, possible that respondents who chose not to use FWA solutions to their work-life interface problems have ascertained that this non-use of FWA increases the perceived security of their jobs. Consequently individual employees might well be obliged to use FWAs as a 'trade-off' (to balance work and non-work interests) in full knowledge that this will be damaging to their future career prospects and possibly their job security. It follows that this would be deleterious to their engagement with their work.

\section{Limitations}

It is believed that the second phase of our research was influenced by the GFC which occurred in Australia in late 2008. According to a government report (Australian Government 2009) more than 150000 full-time jobs were lost during the GFC in Australia. During this time many Australian workers were confronted by fears for their job security (Rafferty, Schutz and Yu 2010). Therefore, it is possible that the current finding of reduction in use of FWAs at time 2 was influenced by the prevailing economic conditions and that further research may demonstrate alternative findings. This point has also been observed elsewhere (Brough et al. 2013).

A second limitation of the current research concerns the low response rates; this is a widely recognised problem of research involving self-report surveys, which according to Krosnick (1999) would not necessarily affect substantive conclusions. Sample responses were generally found to be representative of each organisation's general employee profiles in key demographic details. Finally, with the exception of turnover intentions, the current study reveals that only a small (but significant) proportion of variance in work engagement and anxiety/depression is explained by workplace culture, supervisor support and use of FWAs. This serves to highlight the synergistic nature of influences affecting the workplace environment and the difficulties faced by researchers in teasing out those that are most influential. In addition, as substantial proportions of turnover intentions, work engagement and anxiety/depression remain unexplained by the model, it is acknowledged that alternative variables must contribute to these outcomes. However, it is also advanced that some variables (such as time expectations in regard to turnover and non-use of FWAs in regard to work engagement) retained their individual influence after controlling for time 1 equivalent variables, and are therefore identified as important contributors which cannot be disregarded (see, Rosenthal and DiMatteo 2001).

\section{Implications for organisational practise}

The literature recommends that organisational provision of FWAs will provide employees with an effective tool to manage their work-life balance with autonomy (De Cieri et al. 2005), thereby reducing employee absenteeism, turnover intentions and job satisfaction (Abbott, De Cieri and Iverson 1998; Allen 2001; Brough, O’Driscoll and Kalliath 2005). The current research, using work engagement as a criterion variable, found that this is not 
necessarily the case. What has been highlighted in the current research is the fact that formal and informal processes within organisations work together. An important implication is that anomalies between these two forms of communication must be addressed in order to achieve well functioning workplaces. Strategies provided by organisations for employees to gain autonomy in regard to their work-life balance must be combined with two-way communication that is sensitive to the perceptions of employees about the implications of using such policies. In addition, it is necessary for organisations to evaluate the effect of FWAs and educate supervisory personnel on the outcomes of such evaluations so that their tangible influence on employee outcomes is better informed.

\section{Theoretical implications}

The current research was conducted at a time where there was a downturn in economic conditions associated with widespread retrenchment (Rafferty, Schutz and Yu 2010). Using a JD-R perspective (Bakker and Demerouti 2007), the fact that one remains employed could be regarded as a resource in periods of difficult/insecure employment. This may then assume a higher profile in personal consciousness than psychosocial features of the work environment. However, an alternative explanation might be that in such times people are more aware of the difficulties facing organisations. In addition, it is possible that during downturns organisations become more communicative in regard to conveying their strategies for negotiating altered circumstances to their employees (Rigby 2003). Therefore, it is possible that the sense of involvement thus afforded may provide employees with emotional and intellectual recognition that encourages best efforts and best thinking (Kim and Mauborgene 1998), thereby contributing to organisational productivity and contributing to work engagement.

\section{Conclusion}

The current research found an inverse relationship between use of FWAs and work engagement. Non-use of FWAs was associated with work engagement. It is possible that the current findings reflect some (temporary) instability in job security as a consequence of the Global Financial Crisis. The observed reduction in use of FWAs may, therefore, represent a sense of reduced job security and consequently a perceived need to be more visible within the workplace to remind management personnel of employees' value. We also found that organisational hindrance had a positive (in the case of time expectations) relationship with employee turnover intentions, which was sustained over time. It is therefore apparent that both organisations and employees adjust their employment expectations in order to ensure organisational survival through tough economic times. Whether this has a long-term impact upon employees use of FWAs will be of interest to assess further.

This research has demonstrated the need for more extensive investigation of FWAs, and workers' motivations for using (or not using) them. Previous work investigating imbalance between work and life has suggested that use of FWAs would be consistent with 
work engagement (e.g. Brough, O'Driscoll and Kalliath 2005; De Cieri et al. 2005). The current study has not found this to be the case. As work engagement is associated with optimal productivity gains (Saks 2006; Schaufeli and Bakker 2003), it is important that those managing organisations become conversant with the type of workplace environment that facilitates such engagement levels.

Carolyn Timms (PhD, James Cook) is a researcher and lecturer at the School of Arts and Social Sciences, James Cook University, Cairns, Australia. Previously, she was post-doctoral fellow on the Work Life Balance Project at Griffith University. Her research interests include healthy work environments and antecedents to work engagement and burnout.

Paula Brough (PhD, Bristol) is a professor of organisational psychology in the School of Applied Psychology at Griffith University. Research areas include: occupational stress, coping, the psychological health of high-risk workers (e.g. emergency service workers, correctional workers), work-life balance, and the effective measurement of psychological constructs.

Michael O'Driscoll (PhD, Flinders) is professor of psychology at the University of Waikato, Hamilton, New Zealand. His primary research interests are in the fields of job-related stress and coping, and work-life balance. More generally, he is interested in work attitudes and behaviours, and the relationship between work and health.

Thomas Kalliath (PhD, Washington Univ, St Louis) is associate professor at the Research School of Management, College of Business and Economics, Australian National University. His research interests include management, work-life balance, work-family conflict and enrichment and work engagement.

Oi Ling Siu (PhD, Liverpool) is professor in behavioural science and head of the Department of Sociology and Social Policy at Lingnan University, Hong Kong. Professor Siu's research interests include occupational health psychology specifically occupational stress and safety, and work-family/ life balance.

Cindy Sit (PhD, Hong Kong) is associate professor of Department of Sports Science and Physical Education at the Chinese University of Hong Kong. Her research interests include participation motivation for physical activity of children with and without disabilities, activity behaviour and physical and psychological health.

Danny Lo (PhD, South Australia) is an assistant professor in accounting at Shue Yan University. His research interests include corporate governance, professional and business ethics, organisational behaviour and culture and accounting research.

\section{References}

Abbott J, H De Cieri and RD Iverson (1998) Costing turnover: Implications of work/family conflict at management level. Asia Pacific Journal of Human Resources 36(1), 25-43. 
Allen TD (2001) Family-supportive work environments: The role of organizational perceptions. Journal of Vocational Behavior 58(3), 414-435.

Australian Government (2009) Keep Australia working. Canberra: Author. http://www.nesa.com.au/ media/11215/keep_australia_working._09._pdf.pdf (accessed 22 January 2014).

Australian Senate House Committee into Infrastructure, Transport, Regional Development and Local Government (2009) The global financial crisis and regional Australia. http:// www.aph.gov.au/binaries/house/committee/itrdlg/financialcrisis/report/gfc\%20final\%20report .pdf (accessed 22 January 2014). http://www.aph.gov.au/binaries/house/committee/itrdlg/ financialcrisis/report/gfc\%20final\%20report.pdf

Bakker AB and E Demerouti (2007) The job demands-resources model: State of the art. Journal of Managerial Psychology 22, 309-328.

Beauregard AT and LC Henry (2009) Making the link between work-life balance practices and organizational performance. Human Resource Management Review 19, 9-22.

Behson SJ (2005) The relative contribution of formal and informal organizational work-family support. Journal of Vocational Behavior 66, 487-500.

Biggs A, P Brough and J Barbour (2013). Strategic alignment with organizational priorities and work engagement: A multi-wave analysis. Journal of Organizational Behavior. doi: 10.1002/ job.1866.

Bolger N, A DeLongis, R Kessler and E Wethington (1989) The contagion of stress across multiple roles. Journal of Marriage and the Family 51(1), 175-183.

Bowen DE and C Ostroff (2004) Understanding HRM-firm performance linkages: The role of the 'strength' of the HRM system. Academy of Management Review 29(2), 203-221.

Brough P (2005) A comparative investigation of the predictors of work-related psychological wellbeing within police, fire and ambulance workers. New Zealand Journal of Psychology 34(2), 127134.

Brough P and R Frame (2004) Predicting police job satisfaction and turnover intentions: The role of social support and police organisational variables. New Zealand Journal of Psychology 33(1), 8-16.

Brough P and M O'Driscoll (2010) Organizational interventions for balancing work and home demands: An overview. Work \& Stress 24, 280-297.

Brough P, MP O'Driscoll and TJ Kalliath (2005) The ability of 'family friendly' organizational resources to predict work-family conflict and job and family satisfaction. Stress and Health 21, 223-234.

Brough P, C Timms, OL Siu, T Kalliath, M O’Driscoll, C Sit, D Lo and CQ Lu (2013). Longitudinal application of the Job Demands-Resources model to psychological strain and engagement in cross-national samples. Human Relations 66(10), 1311-1335.

Carless SA and J Wintle (2007) Applicant attraction: The role of recruiter function, work-life balance policies and career salience. International Journal of Selection and Assessment 15(4), 394404.

Carlson DS, KM Kacmar, JH Wayne and JG Grzywacz (2006) Measuring the positive side of the work-family interface: Development and validation of a work-family enrichment scale. Journal of Vocational Behavior 68(1), 131-164.

Carlson DS, KM Kacmar and KJ Williams (2000) Construction and initial validation of a multidimensional measure of work-family conflict. Journal of Vocational Behavior 56, 249-276.

Casper WJ and LC Buffardi (2004) Work-life benefits and job pursuit intentions: The role of anticipated organizational support. Journal of Vocational Behavior 65, 391-410. 
Casper WJ, KE Fox, TM Sitzmann and AL Landy (2004) Supervisor referrals to work-family programs. Journal of Occupational Health Psychology 9(2), 136-151.

Cook A (2009) Connecting work-family policies to supportive work environments. Group \& Organization Management 34(2), 206-240.

De Cieri H, B Holmes, J Abbott and T Pettit (2005) Achievements and challenges for work/life balance strategies in Australian organisations. International Journal of Human Resource Management 6(1), 90-103.

Denison DR (1996) What is the difference between organizational culture and organizational climate? A native's point of view on a decade of paradigm wars. Academy of Management Review 21(3), 619-654.

Dikkers J, S Geurts, L den Dulk, B Peper and M Kompier (2004) Relations among work-home culture, the utilization of work-home arrangements, and work-home interference. International Journal of Stress Management 11(4), 323-345.

Goldberg DP (1972) The detection of psychiatric illness by questionnaire. Oxford University Press, Oxford.

Haggerty J and P Wright (2010) Strong situations and firm performance: A proposed re-conceptualization of the role of the HR function. In A Wilkinson, N Bacon, T Redman and S Snell (eds) The Sage handbook of human resource management, 100-114. Sage Publications, London.

Hall DT (1990) Promoting work/family balance: An organization-change approach. Organizational Dynamics 18, 5-18.

Harter JK, FL Schmidt and TL Hayes (2002) Business-unit-level relationship between employee satisfaction, employee engagement, and business outcomes: A meta-analysis. Journal of Applied Psychology 87(2), 268-279.

Kalliath T, M O'Driscoll and P Brough (2004) Confirmatory factor analysis of the General Health Questionnaire-12. Stress and Health 20(1), 11-20.

Kanter EM (1977) Men and women of the corporation. Perseus, New York.

Kim WC and R Mauborgene (1998) Procedural justice, strategic decision making, and the knowledge economy. Strategic Management Journal 19, 323-338.

Kirby EL and KJ Krone (2002) 'The policy exists but you can't really use it': Communication and the structuration of work-family policies. Journal of Applied Communication Research 30(1), 50-77.

Krosnick JA (1999) Survey research. Annual Review of Psychology 50, 537-567.

Lapierre LM and TD Allen (2006) Work-supportive family, family-supportive supervision, use of organizational benefits, and problem-focused coping: Implications of work-family conflict and employee well-being. Journal of Occupational Health Psychology 11(2), 169-181.

Laschinger HKS and J Finegan (2005) Using empowerment to build trust and respect in the workplace: A strategy for addressing the nursing shortage. Nursing Economics 23(1), 6-13.

Maslach C, WB Schaufeli and MP Leiter (2001) Job burnout. Annual Review of Psychology 52, 397422.

May DR, RL Gilson and LM Harter (2004) The psychological conditions of meaningfulness, safety and availability and the engagement of the human spirit at work. Journal of Occupational and Organizational Psychology 77(1), 11-37.

McDonald P, B Pini and L Bradley (2007) Freedom or fallout in local government? How work-life culture impacts employees using flexible work practices. International Journal of Human Resource Management 18(4), 602-622. 
O'Driscoll M (2000) Work and family transactions. In P Koopman-Boyden, A Dharmalingam, B Grant, V Hendy, S Hillcoat-Nallétamby, D Mitchell, M O’Driscoll and S Thompson (eds) Transactions in the mid-life family, 92-112. Population Association of New Zealand, Hamilton.

O'Driscoll M and P Brough (2010) Work organisation and health. In S Leka and J Houdmont (eds) Occupational health psychology, 57-87. Wiley-Blackwell, Chichester.

O'Driscoll M, P Brough and T Kalliath (2004) Work/family conflict, psychological well-being, satisfaction and social support: A longitudinal study in New Zealand. Equal Opportunities International 23(1/2), 36-56.

Parker CP, BB Baltes, SA Young, JW Huff, RA Altmann, HA Lacost and JE Roberts (2003) Relationships, psychological climate perceptions and work outcomes: A meta-analytic review. Journal of Organizational Behavior 24, 389-416.

Peetz D and C Allan (2005) Flexitime and the long-hours culture in the public sector: Causes and effects. Economic and Labour Relations Review 15(2), 159-180.

Rafferty M, H Schutz and S Yu (2010) Staffing cutbacks in the South Australian public sector and their likely effects: Results of a survey of state public sector employees. Faculty of Economics and Business, Sydney University, Sydney.

Rigby D (2003) Management tools survey 2003: Usage up as companies strive to make headway in tough times. Strategy and Leadership 31(5), 4-11.

Rosenthal R and MR DiMatteo (2001) Meta-analysis: Recent developments in quantitative methods for literature reviews. Annual Review of Psychology 52, 59-82.

Ryan RM and EL Deci (2000) Self-determination theory and the facilitation of intrinsic motivation, social development and well-being. American Psychologist 55, 68-78.

Ryan RM and EL Deci (2001) On happiness and human potentials: A review of research on hedonic and eudaimonic well-being. Annual Review of Psychology 52, 141-166.

Saks AM (2006) Antecedents and consequences of employee engagement. Journal of Managerial Psychology 21(7), 600-619.

Salanova M and WB Schaufeli (2008) A cross-national study of work engagement as a mediator between job resources and proactive behaviour. International Journal of Human Resource Management 19, 116-131.

Schaufeli WB (2004) The future of occupational health psychology. Applied Psychology: An International Review 53(4), 502-517.

Schaufeli WB and AB Bakker (2003) Utrecht Work Engagement Scale: Preliminary manual. Occupational Health Psychology Unit, Utrecht University, Utrecht.

Sonnentag S, I Kuttler and C Fritz (2010) Job stressors, emotional exhaustion, and need for recovery: A multi-source study on the benefits of psychological detachment. Journal of Vocational Behavior 76, 355-365.

Sonnentag S, EJ Mojza, C Binnewies and A Scholl (2008) Being engaged at work and detached at home: A week-level study on work engagement, psychological detachment, and affect. Work and Stress 22(3), 257-276.

Thompson BM, P Brough and H Schmidt (2006) Supervisor and subordinate work-family values: Does similarity make a difference? International Journal of Stress Management 13(1), 45-63.

Thompson CA, EW Jahn, RE Kopelman and DJ Prottas (2004) Perceived organizational family support: A longitudinal and multilevel analysis. Journal of Managerial issues 16(4), 545-565.

Thornthwaite L (2004) Working time and work-family balance: A review of employees' preferences. Asia Pacific Journal of Human Resources 42(2), 166-184. 
Timms C and P Brough (2013). 'I like being a teacher': Career satisfaction, the work environment and psychological health. Journal of Educational Administration 51(6), 768-789.

Timms C, C Lankshear, N Anderson and L Courtney (2008) Riding a hydra: Women ICT professionals' perceptions of working in the Australian ICT industry. Information Technology and People 21(2), 155-177. 